\title{
CHARACTERISTIC AND TYPOLOGY OF CROWD MOTIVATORS TO CROWSOURCING PLATFORM CONTRIBUTION
}

\author{
ANNA SZWAJLIK \\ University of Szczecin, Faculty of Management and Economics of Services, POLAND \\ e-mail: anna.szwajlik@wzieu.pl \\ RECEIVED \\ 18 January 2018 \\ ACCEPTED \\ 2 September 2018 \\ JEL \\ CLASSIFICATION \\ Q31 \\ KEYWORDS \\ crowdsourcing, crowd motivation \\ ABSTRACT The first part of this article discusses the concept of crowdsourcing based on classification of tasks and mo- \\ tivators of crowd participants. The second part describes the results of a crowdsourcing platforms analysis, \\ whose aim was to help determine ways to motivate crowd participants, in relation to the specified typology \\ of performed tasks.
}

\section{Introduction}

Crowdsourcing is a concept of engaging a motivated crowd to carry out tasks of varying degrees of complexity. The development of Internet technology has revealed numerous distributed resources that are at the disposal of online communities. The key resources from the organization's point of view are knowledge, creativity and free time, which, when combined with intrinsic motivators of participants, may lead to the implementation of tasks 
at a higher level of efficiency. The examples of organizations that effectively use the combination of the abovepresented factors are crowdsourcing platforms.

The aim of this article is to present the essence of crowd motivation in the context of tasks carried out within crowdsourcing. The paper uses the methods of literature review, case study analysis and synthesis.

\section{Crowdsourcing typology by character and complexity of tasks carpied out by a crowd}

Engaging a crowd from outside the organization into implementation of tasks previously assigned to employees of the company on the basis of voluntary cooperation has become a completely new paradigm of company management (Howe, 2008, pp. 23-47). As the main creator of crowdsourcing concept, J. Howe defines it as the act of a company or institution taking a function once performed by employees and outsourcing it to an undefined (and generally large) network of people in the form of an open call (Howe, 2006, p. 5). J. Howe classifies crowdsourcing by types of resources possible to be obtained from a crowd, namely knowledge, creativity, finance, and opinions (Brabham, 2013, pp. 75-80). A different approach is presented by Brabham, who defines crowdsourcing as a strategic model to attract an interested, motivated crowd of individuals capable of providing solution superior in quality and quantity to those that even traditional forms of business can (Brabham, 2008, pp. 85-90). In his works, the author underlines the crowdsourcing typology that is based on the nature of tasks carried out by a crowd. He also emphasizes that the manner and type of tasks carried out by a crowd are significantly related with the motivation of individual crowd participants. (Brabham, 2013, pp. 85-90).

Table 1. A problem-focused crowdsourcing typology

\begin{tabular}{lll}
\hline \multicolumn{1}{c}{ Type } & \multicolumn{1}{c}{ How it works } & \multicolumn{1}{c}{ Kinds of problems } \\
\hline $\begin{array}{l}\text { Knowledge discovery and } \\
\text { management }\end{array}$ & $\begin{array}{l}\text { Organization tasks a crowd with finding and } \\
\text { collecting information into a common location and } \\
\text { format }\end{array}$ & $\begin{array}{l}\text { Ideal for information gathering, organization, and reporting } \\
\text { problems, such as the creation of collective resources }\end{array}$ \\
\hline Broadcast search & $\begin{array}{l}\text { Organization tasks a crowd with solving empirical } \\
\text { problems }\end{array}$ & $\begin{array}{l}\text { Ideal for ideation problems with empirically provable } \\
\text { solutions, such as scientific problems }\end{array}$ \\
\hline Peer-vetted creative production & $\begin{array}{l}\text { Organization tasks a crowd with creating and } \\
\text { selecting creative ideas }\end{array}$ & $\begin{array}{l}\text { Ideal for ideation problems where solutions are matters } \\
\text { of taste or market support, such as design or aesthetic } \\
\text { problems }\end{array}$ \\
\hline $\begin{array}{l}\text { Distributed human intelligence } \\
\text { tasking }\end{array}$ & $\begin{array}{l}\text { Organization tasks a crowd with analyzing large } \\
\text { amounts of information }\end{array}$ & $\begin{array}{l}\text { Ideal for large-scale data analysis where human intelligence } \\
\text { is more efficient or effective than computer analysis }\end{array}$ \\
\hline
\end{tabular}

Source: Brabham (2013).

The implementation of tasks regarding knowledge discovery and management is possible when a crowd is engaged in working towards joint projects concerning small communities, municipalities and towns. In this case, collective engagement in problem solving and information collection is more important than the activity of a single crowd participant. The effectiveness of problem solving depends on the amount and accuracy of information obtained by the crowd participants. On the other hand, broadcast search concerns tasks that require, first and foremost, expert knowledge of crowd participants and creative approach to problem solving. For the above reasons, individual crowd participants who accept the challenge and try to win on a competitive basis with other participants are becoming more important. 
Peer-vetted creative production may be adapted for tasks that require the skills of designing and creating artistic visions, ideas and solutions that are often based on aesthetic impressions. By solving tasks from a particular group, crowd participants additionally take part in a complete process that includes such stages as creating, evaluating and selecting ideas. In turn, distributed human intelligence tasking concerns simple activities. In this case, of great importance is the size of crowd, with efficiency and correctness of the tasks performed constituting a key challenge for individual participants.

As presented in the typology of tasks carried out in crowdsourcing, strict demands are imposed on crowd participants, and thus their identification and characterization becomes more significant. There is consensus among researchers concerning the fact that a crowd does not constitute a homogeneous mass consisting only of amateurs. J. Howe indicated that there are many self-employed experts among crowd participants. In this context, Ch. Leadbeater uses the term "professional amateurs", i.e., people who are enthusiasts in a given area, possess specialised skills or knowledge, which are, however, not always evidenced in a formal way, e.g. by an academic degree (Howe, 2008, pp. 90-98). Depending on the nature of the tasks carried out, the participants of the crowd differ in regards to their level of professionalism. In the case of communities performing tasks on iStockphoto platform, $47 \%$ described themselves as "professional", $23 \%$ as "hobbyist" and $14 \%$ chose the term "amateur" (Brabham, 2013, pp. 85-90). Likewise for InnoCentive platform, where $65 \%$ of providers of the best solutions have a PhD degree, and $20 \%$ have undergone a specialist training, often in the field of science. In view of the above, it can be concluded that the crowd of "specialist amateurs" is a new group of potential employees, who, although operating outside the organization, are ready and motivated to engage in solving tasks of varying complexity.

\section{Motivation of the crowd and the typology of tasks performed in crowdsourcing}

As stated above, a crowd constitutes a heterogeneous group of motivated participants. Numerous research in the scope of group motivation has been carried out with the aim to find the reasons for involvement of online communities in the implementation of tasks of varying difficulty. The research indicated that crowd participants are subject to intrinsic and extrinsic motivations (Battistellaand, Nonino, 2012, p. 557) when performing their tasks. Intrinsic motivation concerns psychological-emotional sphere and includes stimuli that trigger specific, targeted reactions and behaviours of individuals in the crowd. These stimuli comprise, among others, freedom of action, the ability to use own skills (Mazur, 2013, pp. 159-163), agency, the ability to express individual creativity, sense of group membership, as well as joy and fun (Battistellaand, Nonino, 2012, p. 558). Intrinsic motivation leads to longerlasting and stronger satisfaction with the job or the performed task (Brabham, 2013, p. 85). Furthermore, intrinsic motivators generate better quality work carried out by a crowd than extrinsic motivating factors (Brabham, 2013, pp. 85-95). On the other hand, extrinsic motivation is triggered by external incentives such as financial rewards, recognition (Brabham, 2008, pp. 75-95), free products and services, reputation, and increase of professional status (Battistellaand, Nonino, 2012, pp. 558-559). Based on the research carried out in the discussed area, Brabham specifies the following key motivators (Brabham, 2013, p. 76):

- financial rewards,

- developing creative skills,

- establishing relationships and cooperation with other professionals,

- building up experience for future work,

- checking one's competences while solving difficult problems, 
- developing friendships,

- sharing with others,

- fun.

As the researchers indicate, there are no ready-made compositions of motivators appropriate for various forms of crowdsourcing (Brabham, 2008, pp. 75-95). Very often the reasons behind crowd participants' decisions are financial incentives, even if they are not high and do not guarantee remuneration at a level comparable to that of workers employed in the traditional way. As indicated by the research on crowd motivation, participants more often undertake activities because of extrinsic and intrinsic motivators (Brabham, 2013, pp. 75-85). This combination is much more likely to affect the satisfaction, which derives from task performance. The following table presents motivators of crowd participants, who carry our tasks on specified crowdsourcing platforms.

Table 2. Motivators of crowd participants, who carry our tasks on specified crowdsourcing platforms

\begin{tabular}{llll}
\hline \multicolumn{1}{c}{ Task typology } & Crowdsourcing platform & \multicolumn{1}{c}{ Task characteristics } & \multicolumn{1}{c}{ Key crowd motivators } \\
\hline $\begin{array}{l}\text { Knowledge discovery } \\
\text { and management }\end{array}$ & SeeClickFix & $\begin{array}{l}\text { Increasing the involvement of citizens } \\
\text { to report problems and solutions in various } \\
\text { areas of social life }\end{array}$ & $\begin{array}{l}\text { Agency, the possibility to influence the situation, } \\
\text { creating better living conditions of local } \\
\text { communities }\end{array}$ \\
\hline Broadcast search & InnoCentive & $\begin{array}{l}\text { Providing unique solutions to problems } \\
\text { in various fields of science. }\end{array}$ & $\begin{array}{l}\text { Financial rewards. } \\
\text { Satisfaction from solving difficult problems. } \\
\text { Participation in a community of professional } \\
\text { connected solvers }\end{array}$ \\
\hline $\begin{array}{l}\text { Peer-vetted creative } \\
\text { production }\end{array}$ & ThreadLess & $\begin{array}{l}\text { Designing graphics for t-shirts. } \\
\text { Voting and selecting the best projects }\end{array}$ & $\begin{array}{l}\text { Financial rewards. } \\
\text { Developing creative skills. } \\
\text { Participating in a community of creative people }\end{array}$ \\
\hline $\begin{array}{l}\text { Distributed human } \\
\text { intelligence tasking }\end{array}$ & Clickworkers & $\begin{array}{l}\text { Creating, proofreading and translating texts. } \\
\text { Collecting and segregating information. } \\
\text { Sharing opinions, participating in surveys }\end{array}$ & $\begin{array}{l}\text { Financial rewards. } \\
\text { Gaining experience and developing competences }\end{array}$ \\
\hline
\end{tabular}

Source: own work.

In the case of tasks requiring the involvement of specialist knowledge, financial incentives play an important role. It is worth noting that payment for the winning idea should be high, as the essence of the task comes down to the complexity of the problem. As indicated by the research, an important motivation to act for crowd participants is the challenge itself, ability to test one's skills, as well as a chance to compete with other solvers. The reason why participants carry out tasks requiring creation of unique, aesthetics design projects is that they need to prepare a portfolio of completed works as well as to improve their skills. Crowd participants are aware that the payment for the task will depend on the degree of their involvement and professionalism. Different motivators are related to making decisions on carrying out micro tasks, of which the key ones are financial rewards often combined with convenient working conditions and, in particular, the freedom to decide about the place and time of performing the task. Motivators which result in crowd involvement in the above-described social tasks, where collecting and sharing information constitute the crux, are strongly related to intrinsic motivation. The intrinsic motivators deserve special attention in this case, as the participants, acting for the benefit of local communities, are often motivated by agency and the need to have a real impact on changing living conditions. 


\section{Analysis of activities related to the acquisition and motivation of crowd participants on crowdsourcing platiorms}

Crowdsourcing platforms, which implement the business model based on engaging a crowd of participants in performance of strictly defined tasks, were subject to netnography research. The aim of this research was to identify ways to engage and motivate a crowd to perform tasks that are a key element of the offer of selected crowdsourcing platforms. The analysis included platforms chosen in accordance with the described typology of tasks proposed by Brabham.

The core of crowdsourcing platforms constitutes engaging a crowd of participants in implementation of given tasks on the basis of voluntary cooperation. In practice, this implies involvement of a big group of people located in different parts of the world. Effective interaction with a dispersed crowd of participants forces crowdsourcing platforms to develop both the appropriate tools for communication and implementation of commissioned tasks, as well as clarify the terms of cooperation. Taking into consideration the above-described characteristics of crowd, platforms, acting as organizations, should strive to engage participants that are selected in accordance with the typology of tasks assigned to a particular crowdsourcing platform.

In the case of crowdsourcing platforms that commission micro-tasks, it is essential that the tasks are performed flawlessly and efficiently. For these reasons, the above-described Clickworker platform, when engaging the crowd participants, initially accepts all users who have declared their willingness to cooperate and defined their competences. Each participant can choose the type of task and the time needed for its completion. Next, the task performed by the participant is checked in terms of correctness and efficiency of implementation. In this way, the best users can qualify to the premium group, where attractive tasks are assigned to people with better rating. This makes it possible for the involved participants to be better rewarded and get more interesting tasks, whereas the platform gains motivated, efficient participants. A different example of a micro task platform is TestBirds. Its users are entrusted with testing ideas and products from various brands. The diligence and engagement of testers result in their inclusion into "Top Tester" groups, where interesting innovative projects are often implemented. The crowd involved in TestBirds platform does not only receive financial rewards for completed orders, but also has the chance to participate in exceptional tasks, which, as the opinions of the participants indicate, is a strong motivator. In both described cases, the crowd participants are focused on financial rewards and convenience of carrying out tasks, whereas conditions for the cooperation proposed by platforms relate to the key motivators as indicated by the acquired crowd of participants.

InnoCentive crowdsourcing platform engages a crowd of solvers by offering them a high financial reward for the best solution, as well as including the winner into the group of distinguished solvers. Furthermore, all users, who implement tasks on InnoCentive platform, create a community of solvers, which is supported by mentors belonging to the aforementioned platform.

Crowdsourcing platforms which engage a crowd to implement creative design ideas, advertise, first and foremost, the opportunity to participate and achieve victory in a competition for the best project, present ideas to a wider group of recipients, have projects evaluated by other creators, as well as obtain a reward for the winning project. An example of such platform is ThreadLess, where the engaged crowd very often plays the role of creators, opinion leaders and promoters of graphic ideas. Another platform that works similarly is $99 \mathrm{designs,} \mathrm{which} \mathrm{engages}$ designers and graphic designers from all over the world to solve graphic tasks. Although crowd participants 
belonging to this platform receive a relatively low financial reward, by taking part in the contest, they can present their previous achievements to a wide group of potential buyers. A different way of engaging a crowd in task completion is implemented by SeeClickFix crowdsourcing platform, whose participants include citizens, residents of cities, districts or regions. The platform provides mainly tools to facilitate the collection and transfer of information necessary to solve a problem, make a decision, or develop a project for specific communities. At the same time, it should be stressed that SeeClickFix concentrates mainly on the intrinsic motivation of its users, who, because of the agency, commit themselves to social activities.

As it becomes clear from the analysis above, crowdsourcing platforms involve a crowd to carry out tasks while taking into account two important factors:

- type and complexity of the task assigned to a crowd,

- crowd characteristics, with particular emphasis put on motivators evoking the willingness of individual participants to take actions.

In practice, this means that as the complexity of the task and the demand for specialist knowledge or creative thinking increase, the importance of intrinsic motivators also becomes more important. Platforms must adapt conditions of co-operation with participants, so that they will support the intrinsic willingness of the crowd to carry out actions. This way of operation is implemented by, among others, InnoCentive and ThreadLess. In the case of a repetitive job, where efficiency and the number of completed tasks are key factors, it is important to design a system of financial rewards offered by a platform, which will reward participants who best meet the above expectations. As stated by the Clickworker employees, the reward scheme implemented by the platform is effective and provides the expected benefits.

It can be seen from the performed research that platforms, operating as online companies, almost in all analysed examples have well-developed rules of cooperation with crowd participants as well as possess appropriate tools. Nevertheless, there can also be observed problems regarding informing about the benefits resulting from starting cooperation, which may, in turn, negatively affect crowd participants' will to get involved in the task. Information in this scope is very often hidden in the platform's resources. Although the examined platforms describe in detail the principles of payment, they forget to present other important information that triggers the will to take action. It must not be forgotten that participants voluntarily undertake a task and often find the examined platforms on their own. Therefore, in order to maintain their interest and find intrinsic motivation, platforms should adapt the way incentives are created and communicated to the characteristics of crowd participants.

\section{Conclusions}

According to the definition presented at the beginning of this article, a motivated crowd may in some parts effectively replace workers who are employed under the generally accepted principles. Premises that support this assessment are:

- motivated participants of the crowd will more willingly and effectively carry out the commissioned activities,

- a larger number of participants acquired for the implementation of the order increases the chances of finding an attractive solution, preparing interesting ideas or implementing a large number of small tasks,

- engaging the motivated crowd can significantly reduce the organization's operating costs.

It should be noted that crowdsourcing works especially well in the two following areas. One of them is the area that requires knowledge and creative thinking, where specialists moved by intrinsic motivators can most often 
be found. The other worth mentioning area is a place where crowd participants undertake small tasks encouraged mainly by financial incentives.

Involving a motivated crowd in carrying out tasks can also take place in traditionally organized enterprises and support, inter alia, activities in the areas of innovation and marketing development. Engaging the motivated crowd from outside the company means going beyond generally accepted ways and standards regarding the company's activities. It is also an expression of openness and the ability to build relationships between the organization and the environment.

\section{References}

Battistellaand, C., Nonino, F. (2012). Open innovation web-based platforms: The impact of different forms of motivation on collaboration. Innovation: Organization \& Management, 14 (4), 557-575.

Brabham, D. (2008). Crowdsourcing as a Model for problem solving. The International Journal of Research into New Media Technologies, 14 (1), 75-90.

Brabham, D. (2013). Crowdsourcing. Cambridge: Massachusetts Institute of Technology.

Howe, J. (2006). The rise of Crowdsourcing. Wired Magazine, 14 (6).

Howe, J. (2008). Crowdsourcing: Why the Power of the Crowd Is Driving the Future of Business. New York: Crown.

Mazur, M. (2013). Motywowanie pracowników jako istotny element zarządzania organizacją. Nauki Społeczne, 2 (8), 156-182.

Cite this article aS: Szwajlik, A. (2018). Characteristic and typology of crowd motivators to crowdsourcing platform contribution. European Journal of Service Management, 3 (27/2), 445-451. DOI: 10.18276/ejsm.2018.27/2-54. 